\title{
A case of prostatic carcinosarcoma with cytological and immunohistochemical findings
}

Kenji Niwa ${ }^{1,2^{*}}$, Sakae Mori ${ }^{1}$, Yoshio Yamaguchi ${ }^{1}$, Shigeaki Yokoi ${ }^{3}$ and Takuji Tanaka ${ }^{4}$

*Correspondence: kniwa.gujo913@gmail.com

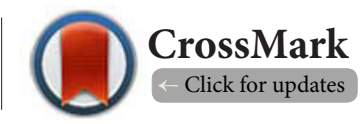

1Section of Laboratory Medicine, Gujo City Hospital, 1261 Shimadani, Gujo City, Japan.
2Department of Obstetrics \& Gynecology, Gujo City Hospital, 1261 Shimadani, Gujo City, Japan.
3Department of Urology, Gifu University Graduate School of Medicine, 1-1 Yanagido, Gifu City, Japan.
${ }^{4}$ Department of Diagnostic Pathology \& Research Center of Diagnostic Pathology, Gifu Municipal Hospital, Gifu City, Japan.

\begin{abstract}
Prostatic carcinosarcoma (PCS) is an extremely rare malignancy and is reported to have a very poor prognosis. A 77-year-old Japanese male was diagnosed as PCS containing two components, adenocarcinoma and leiomyosarcoma by the immunohistochemical analysis. Cytology was initially useful for the diagnosis. Treatments with androgen ablative and surgical therapies could not improve the patient's life, and he died at 12 months after the first visit.
\end{abstract}

Keywords: Prostate, carcinosarcoma, cytology, immunohistochemistry

\section{Background}

Prostate cancer which is often found after elevation of serum prostate-specific antigen (PSA) value, is one of the most common cancers in men. Morphologically, most of the prostate cancers are adenocarcinoma $[\mathbf{1}, \mathbf{2}]$, although non-epithelial malignancies are known to develop in the prostate [3] with an incidence of less than $0.1 \%$ of all prostate malignancies [4]. Prostatic carcinosarcoma (PCS) which was first reported in 1967 by Hamlin and Lund [5], is an extremely rare malignancy and has very poor prognosis with a survival of approximate 7 months [6-9]. PCS is a histological mixture of adenocarcinoma and certain type(s) of sarcoma $[\mathbf{1}, \mathbf{2}, \mathbf{1 0}]$. Approximate less than 100 PCS cases have been reported in the prostate [4]. Some PCSs may also be referred to as sarcomatoid carcinoma $[6-9,11]$. Also, only a few studies on the cytological and immunohistochemical findings of this rare malignancy were described $[12,13]$.

We report here cytological, histopathological, and immuohistochemical findings of PCS which developed in a old Japanese man.

\section{Case presentation}

A 77-year-old Japanese male noticed macro-hematuria and visited to the Department of Urology in our hospital. On digital rectal examination, a diffusely enlarged lesion on the left lobe of the prostate was palpable. Serum PSA was slightly elevated:
$4.03 \mathrm{ng} / \mathrm{dL}(<4 \mathrm{ng} / \mathrm{dL})$.

MRI showed a cystic lesion with irregular margin on the left lobe of the prostate and partially invaded over the outer layer (Figure 1). A subsequent biopsy revealed Gleason 5 $(3+2)$ adenocarcinoma (Figure 2$)$ of the prostate. The patient was diagnosed as T3aNOMO prostate adenocarcinoma by the contrast $\mathrm{CT}$, bone scintigraphy and $\mathrm{MRI}$, and wanted to receive an endocrine therapy. Two months after his first visit, the LH$\mathrm{RH}$ analogue therapy was started. Although the serum PSA level decreased to normal levels at 8 months after the start of the therapy, the patient complained of urinary obstruction. $M R I$ revealed an enlarged prostatic lesion, and trans-urethral resection of the prostate (TUR-P) was performed for the purpose of release of the urinary obstruction. A total amount of $35 \mathrm{~g}$ prostate was resected. Histopathological examination on the TUR-P specimen showed neoplasm consisted of a mixture of carcinomatous and sarcomatous components. The carcinomatous component (Figure $\mathbf{3 A}$ ) was well - moderately differentiated prostatic adenocarcinoma, showing a positive reaction against the antibody of PSA. On the other hand, the sarcomatous component (Figure 3B) was consisted of spindle-like cells with marked nuclear atypia. These spindle-like tumor cells were positive for a-smooth muscle action (a-SMA) (Figure 3C) and desmin (Figure 3D). We observed tumor cell necrosis and 17 mitotic figures including abnormal division figures per 10 


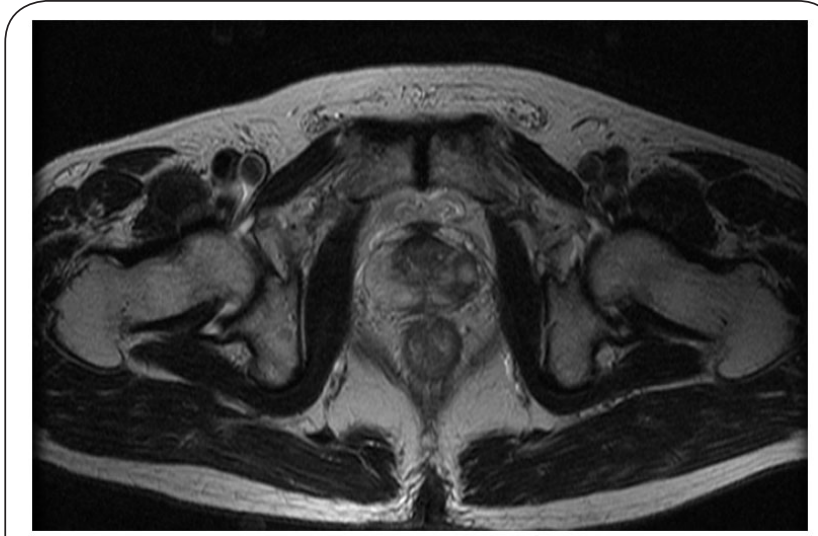

Figure 1. Transverse view of pelvic MRI-T2.

A cystic prostatic lesion with irregular margin on the left lobe partially invaded over the outer layer.

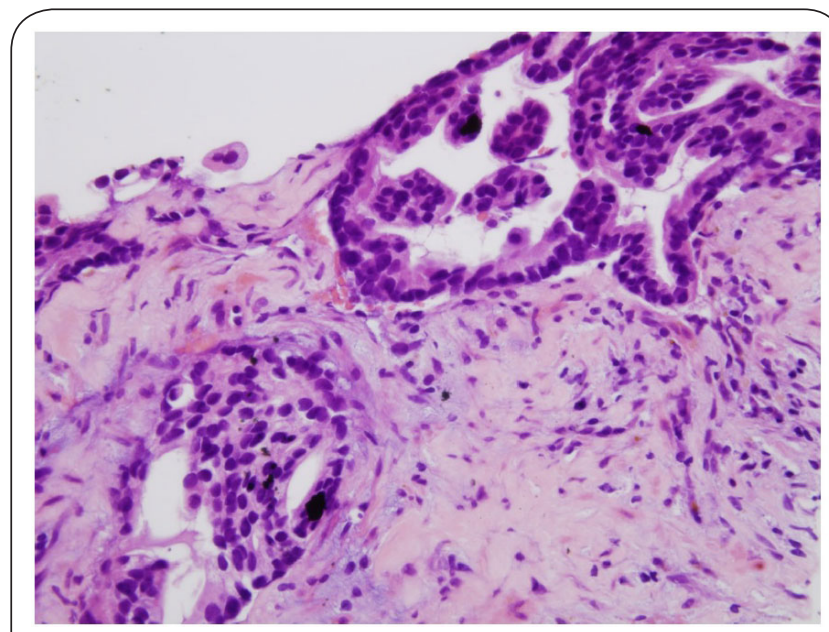

Figure 2. Histopathology of the biopsy specimens.

Note: Gleason $5(3+2)$ adenocarcinoma. H\&E stain (original magnification, $\mathrm{x} 200)$.

high-power fields (hpf). These findings suggested that sarcomatous component was leiomyosarcoma.

Heterogeneous components, such as osteosarcoma and osetosarcoma could not be found. Retrospective examination of the prostatic biopsy showed the presence of non-epithelial atypical cells (Figure 4) with weakly positive reaction with SMA. Thus, the patient could be diagnosed as PCS at his first visit. Although TUR-P had been performed, the tumor rapidly enlarged and obstruction of the urine occurred again. Therefore, the total pelvic exenteration (PE) with cutaneous ureterostomy and colostomy were performed. Macroscopically, the resected prostate tumor was measuring $8 \times 4.5 \times 4 \mathrm{~cm}$ (Figure 5), and the surgical margins were free from the tumor. Cytology of the cut-surface of the tumor at the PE revealed the presence of two types of tumor cells with different origin: one was an adenocarcinoma like cells with a sheet formation (Figure 6A), and the other was big sarcomatous cells with a marked nuclear

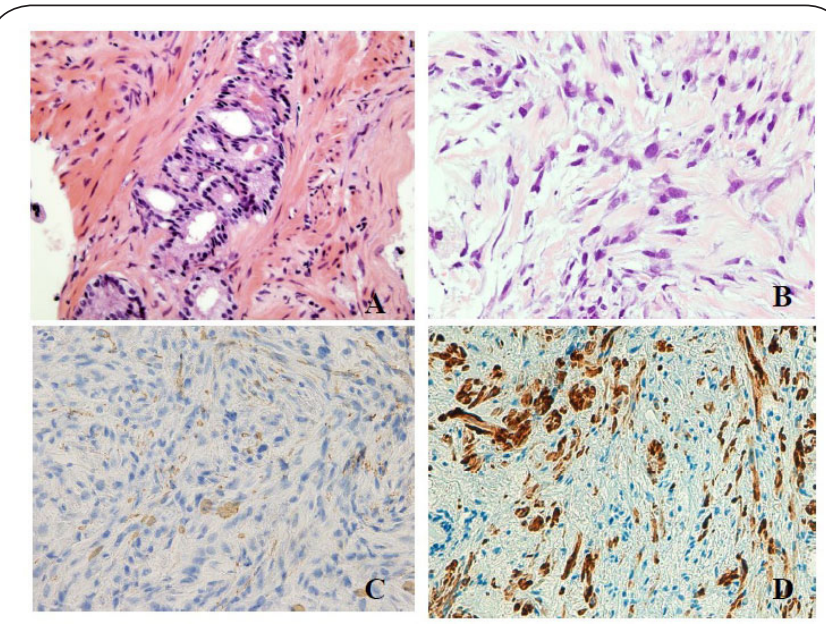

Figure 3. Histopathology of the trans-urethral resection of the prostate (TUR-P) specimen.

Prostatic lesion contains (A) Gleason $5(3+2)$, adenocarcinoma and (B) spindle-like sarcomatous cells which are immunohistochemicaly positive for (C) $\alpha$-smooth muscle actin (a-SMA) and (D) desmin. (A) H \& E stain (original magnification, x160); (B) H \& E stain (original magnification, x200); (C) immunohistochemistry of a-SMA (original magnification, x80); and (D) immunohistochemistry of desmin (original magnification, x80).

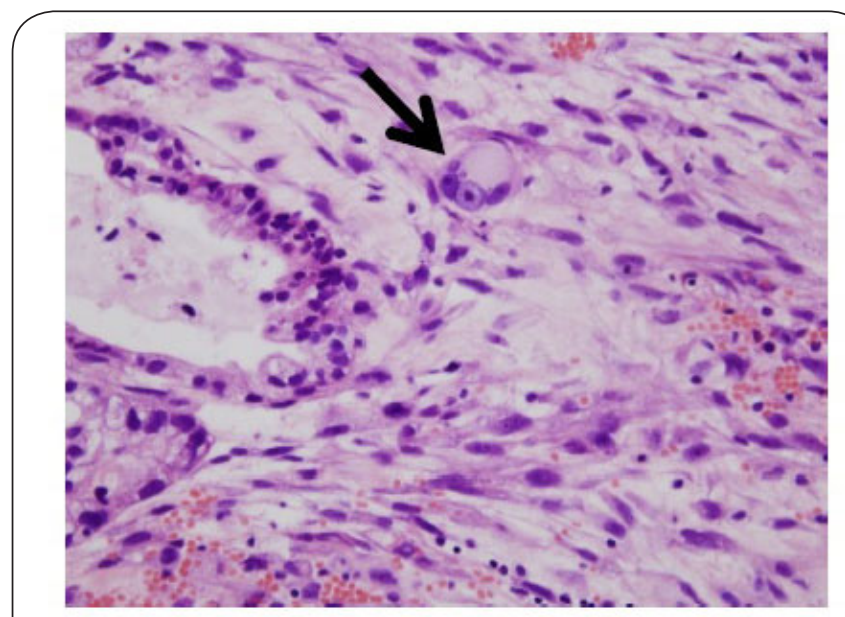

Figure 4. Re-examination of the first biopsy specimen shows the presence of a few sarcomatous atypical cells (arrow) with multi-nuclei. H \& E stain (original magnification, x200).

atypia and several nucleoli (Figure 6B). Histopathological examination of the PE specimen also showed a mixture of carcinomatous and sarcomatous components (Figure 7A). The carcinomatous component was well-moderately differentiated tubular/acinar adenocarcinoma with a positive reaction with PSA (Figure 7B). In addition, the sarcomatous component, which had 19 mitotic figures including abnormal division figures per $10 \mathrm{hpf}$, was spindle-like cells with marked nuclear atypia. They showed positive reactivity of a-SMA 


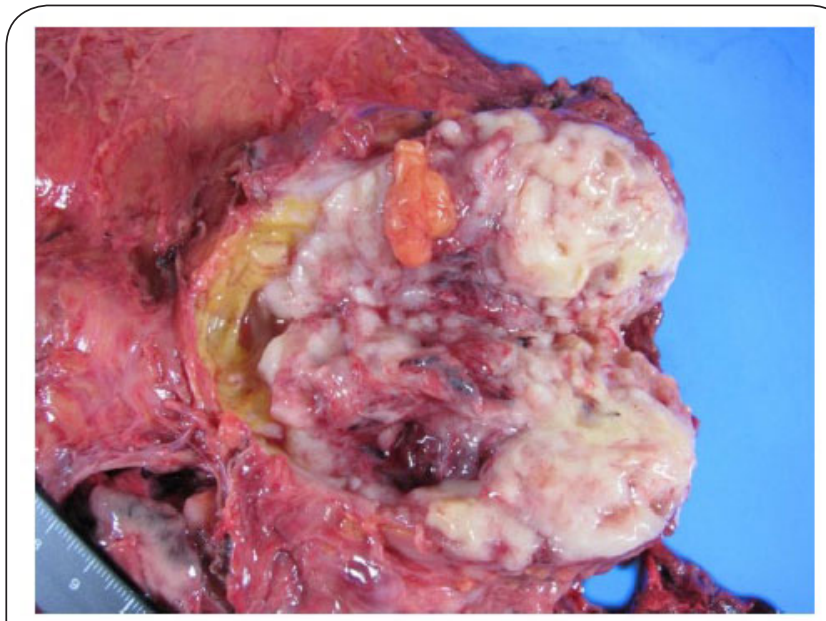

Figure 5. Cut-surface of the resected tumor. Note whitish gray tumor with hemorrhage is noted.

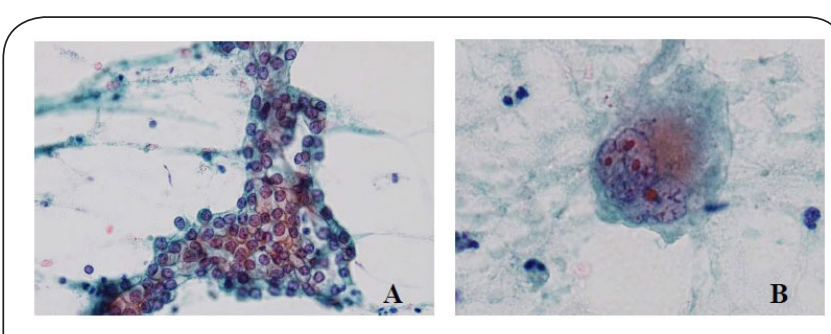

Figure 6. Touch smears from the cut-surface of the resected tumor. (A) A sheet of glandular cells with slight atypia suggesting of well-differentiated adenocarcinoma. (B) A multinucleated large sarcomatous cell with marked nuclear atypia and prominentl nucleoli. (A) Papanicolaou stain (original magnification, x400); and (B) Papanicolaou stain (original magnification, $\mathrm{x} 400$ ).

(Figure 7C) and desmin (Figure 7D) patient was detected as a local recurrence and died at 12 months after the first visit, although we did not detect distant metastasis.

\section{Discussion}

The origin and pathogenesis of PCSs is still unknown; some authors proposed that both carcinoma and sarcoma simultaneously developed within the prostate, while others suggested that adenocarcinoma underwent transformation into sarcoma $[\mathbf{7}, 9,14,15]$. The present case was suggested to be the latter case from the findings of histopathological re-examination of the biopsy. A recent report by Rodrigues, et al. [16] described deletion of a prostate-specific erythroblast transformation-specific (ETS)-related gene in both the sarcomatous and adenocarcinoma, suggesting that PCSs are derived from prostate epithelium.

Although half of PCSs have developed in patients with a history of prostatic adenocarcinoma [6,8], immunohistocehmical examinations was performed in a few cases $[12,13]$. In our case, we observed multi-nucleated large sarcomatous cells

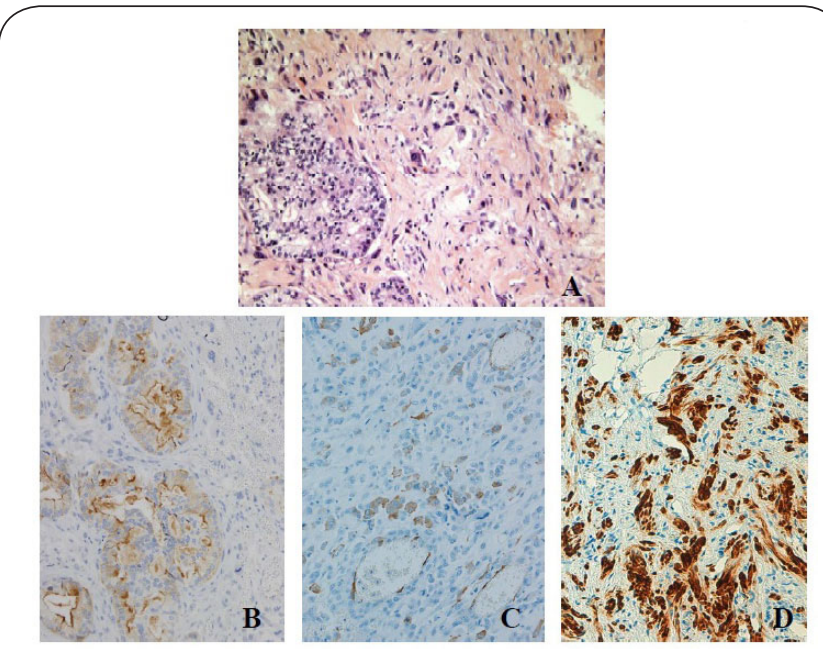

Figure 7. Histopathology of the resected tumor consisting of (A) a mixture of carcinomatous and sarcomatous components. Immunohistocvhemistry shows (B) positive reaction of PSA in the adenocarcinoma cells, $(\mathbf{C})$ positive reaction of $\alpha$-SMA in the sarcoma cells and (D) positive reactivity of desmin. (A) $\mathrm{H} \& \mathrm{E}$ stain (original magnification, x80); (B) immunohitochemistry of PSA (original magnification, x160); (C) immunohistochemistry of a-SMA (original magnification, $\mathrm{x} 80$ ); and (D) immunohistochemistry of desmin (original magnification, $\mathrm{x} 80)$.

as well as adenocarcinoma cells on the Papanicolaou-stained stamp smears form the cut-surface of the resected tumor. The prostatic tumor was initially diagnosed as adenocarcinoma in the biopsy specimen. The TUR-P pathological specimen showed a mixture of carcinomatous with a positive reaction of PSA and sarcomatous components with a positive reaction of a-SMA. Retrospective analysis of the biopsy specimen revealed a weakly positive reaction with a-SMA in the spindle cells. The PE pathological specimen and cytological findings also confirmed the primary PCS in the prostate.

We performed cytological diagnosis of the present case, as the cytological findings were useful for the diagnosis of the PCS $[12,13]$. In PCSs reported, adenocarcinoma was usually high grade [6]. Interestingly, some cases were reported to be adenosquamous carcinoma, which may be associated with chondrosarcoma development $[6,17]$. The most common sarcomatous component was reported to be osteosarcoma (50-62\%) followed by chondrosarcoma (33-45\%), leiomyosarcoma (17-24\%), and rhabdomyosarcoma (10-12\%) [6,7]. In the present case, the sarcomatous component was leimomyosarcoma based on the immunohistochemical findings showing positive reaction with a-SMA. From the cytological findings, the epithelial component was diagnosed as adenocarcinoma, however the sarcomatous one could not be diagnosed as leiomyosarcoma because of the presence of a few sarcoma cells.

The mean age at the diagnosis of PCSs is 66 year-old, and the survival period was extremely short, being approximate 
Niwa et al., Pathology Discovery 2017,

7 months $[7,18]$. The most commone site of metastasis of PCSs was the lung (43\%) [7]. Reported treatment modalities include TUR-P, orchiectomy, chemotherapy, radiation, androgen ablative therapy, prosatetomy, and PE $[7,18]$. However, at present there is no standardized treatment regimen for PCSs.

\section{Conclusion}

An extremely rare case of prostatic carcinosarcoma with a mixture of adenocaricoma and leiomyosarcoma in a 77-yearold man is presented with the histopathology, cytological, and immunohistochemical findings which were useful for the accurate diagnosis. As the prognosis of the tumor is extremely poor, various therapies could not put the patient's life off.

\section{Competing interests}

The authors declare that they have no competing interests.

Authors' contributions

\begin{tabular}{|l|c|c|c|c|c|}
\hline Authors' contributions & KN & SM & YY & SY & TT \\
\hline Research concept and design & $\checkmark$ & -- & -- & -- & -- \\
\hline Collection and/or assembly of data & $\checkmark$ & $\checkmark$ & $\checkmark$ & $\checkmark$ & -- \\
\hline Data analysis and interpretation & $\checkmark$ & $\checkmark$ & $\checkmark$ & $\checkmark$ & -- \\
\hline Writing the article & $\checkmark$ & -- & -- & -- & -- \\
\hline Critical revision of the article & $\checkmark$ & -- & -- & -- & $\checkmark$ \\
\hline Final approval of article & $\checkmark$ & $\checkmark$ & $\checkmark$ & $\checkmark$ & $\checkmark$ \\
\hline Statistical analysis & -- & -- & -- & -- & -- \\
\hline
\end{tabular}

\section{Acknowledgement}

We thank the editor and reviewers for the constructive comments which helped us to improve the manuscript.

\section{Publication history}

EIC: Markus H. Frank, Harvard Medical School, USA.

Received: 07-Feb-2017 Final Revised: 22-Mar-2017

Accepted: 25-Mar-2017 Published: 07-Apr-2017

\section{References}

1. Epstein JI, Algaba F, Allsbrook WCJ, Bastacky S, Boccon-Gibod L, De Marzo AM, Egeva L, Furusato M, Hamper UM, Helpap S, Humphrey PA, Iczkowski KA, Lopez-Beltran A, Montironi R, Rubin MA, Sakr WA, Samaratunga $\mathrm{H}$ and Parkin DM (2004) Chapter 3. Tumours of the prostate. In Eble JN, Sauter G, Epstein JI and Sesterhenn IA (Eds.), Pathology \& Genetics. Tumours of the Urinary System and Male Genital Organs IARC Press, Lyon. 2004; 159-192.

2. Epstein JI, Cubilla AL and Humphrey PA. Variants of prostatic adenocarcinoma. In Epstein JI, Cubilla AL and Humphrey PA (Eds.), Tumors of the Prostate Gland, Seminal Vesicle, Penis, and Scrotum American Registry of Pathology / Armed Foces Institute of Pathology, Washington, DC. 2011; 239-267.

3. Hansel DE, Herawi M, Montgomery E and Epstein JI. Spindle cell lesions of the adult prostate. Mod Pathol. 2007; 20:148-58. | $\underline{\text { Article | PubMed }}$

4. Furlan SR, Kang DJ and Armas A. Prostatic carcinosarcoma with lung metastases. Case Rep Oncol Med. 2013; 2013:790790. | Article | PubMed Abstract | PubMed FullText

5. Hamlin WB and Lund PK. Carcinosarcoma of the prostate: a case report. J Urol. 1967; 97:518-22. I PubMed

6. Dundore PA, Cheville JC, Nascimento AG, Farrow GM and Bostwick DG. Carcinosarcoma of the prostate. Report of 21 cases. Cancer. 1995;
76:1035-42. | Article | PubMed

7. Fukawa T, Numata K, Yamanaka M, Miyamoto T, Kurokawa Y, Kanayama HO, Kagawa S, Utsunomiya M and Hirokawa M. Prostatic carcinosarcoma: a case report and review of literature. Int J Urol. 2003; 10:108-13. | Article | PubMed

8. McGee SM, Boorjian SA and Karnes RJ. Carcinosarcoma of the prostate replacing the entire lower genitourinary tract. Urology. 2009; 74:540-1. | Article | PubMed

9. Rogers CG, Parwani A, Tekes A, Schoenberg MP and Epstein JI. Carcinosarcoma of the prostate with urothelial and squamous components. J Urol. 2005; 173:439-40. I Article I PubMed

10. Mazzucchelli R, Lopez-Beltran A, Cheng L, Scarpelli M, Kirkali Z and Montironi R. Rare and unusual histological variants of prostatic carcinoma: clinical significance. BJU Int. 2008; 102:1369-74. | Article | PubMed

11. Grignon DJ. Unusual subtypes of prostate cancer. Mod Pathol. 2004; 17:316-27. | Article | PubMed

12. Katoh T, Andoh T, Takahashi H, Satoh N, Kubosawa H and Takeda B. A case of carcinosarcoma of the prostate (in Japanese). J. Jpn. Soc. Clin. Cytol. 1994; 33:1135-1139.

13. Wu JH, Tan HW, Chng MJ, Tan PH and Tay KP. Fine needle aspiration cytology diagnosis of metastatic sarcomatoid prostatic carcinoma. Acta Cytol. 2007; 51:937-9. I PubMed

14. Lindboe CF and Klem KH. Carcinosarcoma of the prostate. APMIS. 2006; 114:153-8. | Article | PubMed

15. Yoshida T, Ujike T, Uemura M, Nin M, Nishimura K, Miyoshi S and Kawano K. [Carcinosarcoma of the prostate: a case report]. Hinyokika Kiyo. 2007; 53:817-9. | Article | PubMed

16. Rodrigues DN, Hazell S, Miranda S, Crespo M, Fisher C, de Bono JS and Attard G. Sarcomatoid carcinoma of the prostate: ERG fluorescence in-situ hybridization confirms epithelial origin. Histopathology. 2015; 66:898-901. | Article | PubMed

17. Martin SA, Fowler M, Catalona WJ and Boyarsky S. Carcinosarcoma of the prostate: report of a case with ultrastructural observations. J Urol. 1979; 122:709-11. | PubMed

18. Subramanian VS, Coburn M and Miles BJ. Carcinosarcoma of the prostate with multiple metastases: case report and review of the literature. Urol Oncol. 2005; 23:181-3. | Article | PubMed

\section{Citation:}

Niwa K, Mori S, Yamaguchi Y, Yokoi S and Tanaka T. A case of prostatic carcinosarcoma with cytological and immunohistochemical findings. Pathol Discov. 2017; 5:2. http://dx.doi.org/10.7243/2052-7896-5-2 